\title{
Integrating Spirituality Into Counselor Preparation: A Developmental, Wellness Approach
}

\section{Jane E. Myers and Kirk Williard}

Recent surveys of the general public and of counseling professionals suggest the pervasive importance of spirituality in the lives of all individuals. Yet, the infusion of spirituality in counselor preparation programs continues to be a concern. Incorporating spirituality within a wellness paradigm can help counselors and counselor educators value and address spirituality as an integral component of optimum human functioning. By distinguishing between religiosity and spirituality and operationally conceptualizing spirituality as a life span developmental phenomenon that is essential for achieving wellness, counselor educators can more readily incorporate spiritual issues within the philosophy of the counseling profession.

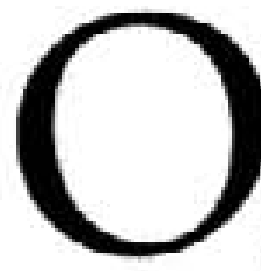

$\mathrm{n}$ the basis of surveys they have conducted since the 1950s, Gallup and Lindsay (1999) concluded that "increasingly in the 1990s religion and spirituality play an important part of our national life." These surveys suggested that more than $80 \%$ of Americans value their religion and that more than $90 \%$ have strong religious beliefs and convictions (Gallup, 1985; Gallup \& Castelli, 1989). Furthermore, most individuals expect or consider these values to be an important part of therapy when the need for helping arises (Bergin \& Jensen, 1990; Lehman, 1993; Myers \& Truluck, 1998; Quakenbos, Privette, \& Klentz, 1985). Although "spiritual and religious issues are therapeutically relevant, ethically appropriate, and potentially significant topics in counseling and counselor education" (Burke et al., 1999, p. 251), Kelly (1997) and Pate and High (1995) estimated that only half of all counselor education programs include these issues in counselor preparation curricula.

Burke et al. (1999) noted that "spirituality, religion, and the counseling profession have had an uneasy relationship" (p. 251). In part, this seems to reflect the confusion that results from equating spirituality and organized religious practices (Myers, Sweeney, \& Witmer, 2000; Myers \& Truluck, 1998), and, in part, it reflects the influence of individuals such as Freud (1912/1959) and Ellis (1991) who, in the past, equated religiosity with mental illness. Regardless of the origins of the problem, the need for preparing counselors to respond to clients' spiritual needs seems to be an increasing reality (see Bishop, 1992; Burke et al., 1999; Kelly, 1994; Pate \& Bondi, 1992).

Jane E. Myers, Department of Counseling and Educational Development, The University of North Carolina at Greensboro; Kirk Williard, Centerpoint Human Services, Danbury, North Carolina. Correspondence concerning this article should be addressed to Jane E. Myers, Department of Counseling and Educational Development, The University of North Carolina at Greensboro, PO Box 26171. Greensboro, NC 27402-6171 (e-mail: jemyers(1)uncg.edu). 
Pate and Bondi (1992) suggested that this need could be addressed by including religious values in course content, providing experiential training in religious values, and collaborating with religious counselors in the training and supervision process. This suggestion was facilitated with the adoption of the 2001 standards for counselor preparation by the Council for Accreditation of Counseling and Related Educational Programs (CACREP, 2001), which include several references to spiritual issues and needs. Burke et al. (1999) provided strategies and examples for infusing spiritual and religious issues in each of the core curriculum areas of the preparation standards. Although these authors provided tangible strategies for infusing spiritual and religious issues into counselor preparation, the philosophical and theoretical bases of these strategies are less apparent than is optimal for counseling students. Because counseling has embraced a developmental, wellness orientation as a core philosophy for training and intervention (e.g., Myers, 1991; Palmo \& Weikel, 1986; Smith, 1999), it seems logical that this orientation can also provide a foundation for preparing counselors to meet the spiritual and religious needs of their clients.

In this article, we discuss spirituality as both a developmental phenomenon and as a central component of wellness. We examine the differences and similarities between religiosity and spirituality and propose a working definition of human spirituality that is compatible with numerous, relevant theoretical models commonly used in counseling. Finally, using a developmental, wellness foundation, we consider implications for counselor preparation in human spirituality.

\section{Spirituality as a Developmental Process}

Numerous theories of human development have been proposed that identify spirituality as a natural developmental process that is tied in various ways to other aspects of human development. For our discussion, these theories are categorized as psychodynamic, psychosocial, and cognitive.

\section{Psychodynamic Theories of Development}

Jung (1933) is considered by many to be the first theorist to incorporate the spiritual dimension into a theory of human functioning and to propose the importance of integrating spirituality into the therapeutic process. He viewed spiritual development as the evolution of the self through merging and reconciliation of the conscious with unconscious forces. This process produces movement from egocentricity toward experience of the genuine self (Mack, 1994). Jung's theories have been impetus for the development and growth of other transpersonal theories of spiritual development that incorporate humanism with Eastern religious thought (Burke et al., 1999; Lukoff, Lu, \& Turner, 1998; Strohl, 1998). 
Rizzuto (1991) and Spero (1992) proposed that human spiritual development may best be understood as an object-relations phenomenon (Burke et al., 1999). In this context, attachment to a supreme being is the foundation for all human relational connections. Relatedly, spiritual growth evolves as a closer relationship is sought with this higher power.

\section{Psychosocial Theories of Development}

In psychosocial models of human growth and change, spiritual development evolves as humans interact with their social and physical environments. Maslow (1970) presented a developmental model in which individuals progressed from a primary focus on having basic physical needs met to self-actualization and, finally, to transcendent self-actualization. Maslow proposed that intrinsic motivation toward the transcendent or spiritual increases as one develops, although few strive for, or reach, a transcendent phase (Grof, 1999).

Erikson (1963) identified spiritual belief and meaning as integral to the process of personal development, a process that is reflected in the individual's movement from trusting others to the development of a mature understanding of life's meaning (Burke et al., 1999). Compatible with this Eriksonian understanding of maturing spirituality, Riker and Myers (1990) identified several spiritual developmental tasks that are associated with later stages of life. These include the Eriksonian notion of striving for integrity, as well as searching for the meaning of life and developing inner peace.

Frankl (1984) proposed that spiritual development occurs as individuals find meaning in work and intimate relationships, and experience unavoidable suffering (Mack, 1994). Nino (1997) proposed that human spirituality is part of a normative developmental process that is integral to Levinson's (Levinson, Darrow, Kline, Levinson, \& McKee, 1978) theory of the development of life structures. These structures are the underlying patterns that are formed in response to social, physical, and personal relationships (Nino, 1997).

\section{Cognitive Theories of Development}

Other theorists whose work has been based primarily on the work of Piaget $(1926 / 1963)$, have proposed that human spiritual development is related to cognitive development. Piaget proposed a series of four cognitive developmental stages that reflect qualitatively different ways of thinking and processing information. Kohlberg (1984) proposed a six-stage theory of moral development that involves a progression from preconventional to principled moral decision making, thus paralleling Piaget's developmental model. Movement from one stage to the next is not possible in the absence of the qualitative changes in thinking that is described in Piaget's theory. Piaget further 
proposed that only $75 \%$ of persons achieve the highest stage of cognitive development, formal operational thinking; thus, by implication, only $75 \%$ of persons will be able to achieve the higher stages in Kohlberg's moral development paradigm.

Fowler $(1981,1991)$ proposed that spiritual faith develops in seven stages as cognitive development progresses. Fowler defined these stages as operations of valuing and knowing that evolve into more complex and comprehensive patterns as new forms of cognition develop. One begins life in the preoperational faith stage of infancy, labeled by Fowler as Primal Faith. As cognitive development begins, one progresses toward full faith development, which is identified as the Universalizing Faith that is present beyond midlife (Young, Cashwell, \& Woolington, 1998).

\section{Comparison of Theories}

Psychodynamic, psychosocial, and cognitive theories of development each provide views of spirituality and spiritual growth on which to base counseling interventions. What is lacking, however, is a unified theoretical approach that (a) integrates the unique contributions of each theory to the study of human development in the spiritual dimension and (b) integrates spirituality with other aspects of human growth and change. Models of wellness establish a paradigm that provides this integration by incorporating aspects of body, mind, and spirit into a holistic view of human functioning.

\section{The Wellness Paradigm}

The concept of wellness incorporates both a concern for optimizing human behavior and functioning and for integrating body, mind, and spirit as part of this process. To understand spirituality as a component of wellness, it is helpful to review common definitions and current models of wellness.

\section{Definitions of Wellness}

Dunn (1961) defined wellness as "an integrated method of functioning which is oriented toward maximizing the potential of which the individual is capable" (p. 4). Hettler (1984) viewed wellness as a process through which individuals make choices for a successful existence; Hettler's definition is similar to Ardell's (1996) view of wellness as a proactive approach to life that optimizes one's potential.

Archer, Probert, and Gage (1987), writing from a more psychological perspective, defined wellness as "the process and state of a quest for maximum human functioning that involves the body, mind, and spirit" (p. 311). Consistent with psychodynamic and psychosocial theories of development (e.g., Jung, 1933; Maslow, 1970), wellness may be viewed as antrinsic 
motivation toward self-actualization and fulfillment. More recently, Myers et al. (2000) defined wellness as

a way of life oriented toward optimal health and well-being, in which body, mind, and spirit are integrated by the individual to live life more fully within the human and natural community. Ideally, it is the optimum state of health and well-being that each individual is capable of achieving. (p. 252)

\section{Models of Wellness}

A number of models have been proposed to explain the myriad factors that combine to create healthy functioning (see Myers, 1992; Witmer \& Sweeney, 1992). Most of these models have their foundation in physical health professions and place primary, although by no means sole, emphasis on physiological aspects of development. Hettler (1984), a public health physician, developed a hexagon model to explain the characteristics of healthy functioning. Chandler, Holden, and Kolander (1992), two counselor educators and an exercise physiologist, adapted Hettler's model to explain spirituality as a developmental phenomenon. Professional counselors Sweeney and Witmer (1991) and Myers et al. (2000), developed a circumplex model that is based on Adlerian theory to explain healthy development and functioning.

Hettler's (1984) Hexagon Model. Hettler proposed that there are six characteristics of human functioning that are essential to achieving wellness: physical, occupational, social, intellectual, emotional, and spiritual. These characteristics are depicted graphically in a hexagon, and each component is equal in size. This model has been used extensively in physical and public health professions to promote understanding of wellness. Although Hettler noted the importance of each area, when the model is used in the health professions, the emphasis has been primarily on physical well-being. Moreover, the emphasis of the model has been on present functioning and not on development over time.

Chandler et al.'s (1992) Model of Spiritual Wellness. Chandler et al. suggested that Hettler's (1984) model should be modified from the original hexagon to a pentagon, with each of five areas making up the segments of the model. In the new model, spirituality is not a separate component but rather an integral component of each of the other five areas. Spirituality is viewed as both the core of wellness and an inseparable part of all wellness dimensions. Furthermore, Chandler et al. proposed that spirituality develops over time as one achieves balance or openness to the pursuit of spiritual wellness.

Sweeney and Witmer's (1991) Wheel of Wellness. Sweeney and Witmer (1991), Witmer and Sweeney (1992), and Myers et al. (2000) proposed a holistic model in which 16 characteristics of healthy functioning are depicted in a wheel. These characteristics were identified through an examination of cross-disciplinary studies that identified healthy behaviors that contribute to longevity, quality of life, and well-being. In this model, spirituality is viewed as the core characteristic of healthy people 
and as central to achieving Adler's (1927/1954) major life tasks of work, friendship, and love. Extending Adler's early research, Sweeney (1998) defined the life task of self-direction, which comprises 12 additional components: (a) sense of worth, (b) sense of control, (c) realistic beliefs, (d) emotional awareness and coping, (e) problem solving and creativity, (f) sense of humor, (g) physical fitness, (h) nutrition, (i) self-care, (j) stress management, (k) gender identity, and (1) cultural identity. Self-direction is the manner in which an individual regulates, disciplines, and directs the self in daily activities and in pursuit of long-range goals. It refers to a sense of mindfulness and intentionality in meeting the major tasks of life. The Wheel model is also ecological in that numerous life forces (e.g., family, community, media) and global events affect the pursuit of wellness.

Myers et al. (2000) recently provided a four-phase strategy for using the Wheel model in counseling to help clients achieve healthy functioning over their life span. As is true of each of the models we discuss in this article, using a wellness perspective in counseling to help clients change requires that clear, concise, working definitions of each of the components of wellness be presented to them. These definitions should be useful to clients with minimal explanation and should also be readily understood by counselors. The lack of a clear definition and confusion over the meaning of spirituality has been a significant obstacle to the inclusion of spiritual concerns in counselor preparation and in counseling practice (Burke et al., 1999; Kelly, 1994; Myers et al., 2000; Pate \& Bondi, 1992).

\section{Defining Spirituality}

In order to incorporate spirituality into counselor preparation programs, the term spirituality must be defined conceptually, then operationalized as a somewhat concrete and observable phenomenon that is valid for the entire human species (Slife, Hope, \& Nebeker, 1999). Without an operational definition of spirituality, professional counselors are left to navigate the oceans of philosophy, science, and theology, whose currents have historically muddied the waters where they meet. To propose that education in the spirituality of human beings is possible demands that the definitive process be one that is inclusive of all approaches to understanding this concept, which, of course, varies across societies and cultures. At the same time, however, the definition must be understandable and useful for counselor educators, practitioners, and counseling students who do not necessarily have comprehensive, formal preparation in areas such as psychology, philosophy, and theology. A useful definition is one that is inclusive of any particular orientation toward the spiritual but exclusive of absolutist ideology that in any way discounts or minimizes any particular orientations, or religious/faith traditions. 


\section{Spirituality and Religiosity}

Both Ellis (1991), in most of his writings, and Freud (1912/1959) equated religiosity and mental illness, thus effectively promoting the view that clients' mention of religious concerns in counseling was inherently negative. As a consequence, one of the major historical obstacles to the inclusion of spirituality in counselor preparation has been widespread confusion between the concepts of religiosity and spirituality, the former being a narrow view incorporating the tenets of specific faith traditions and the latter a broader perspective reflecting the human need for transcendence and connectedness (Burke \& Miranti, 1995; Burke et al., 1999). Myers et al. (2000), for example, made a distinction between spirituality, a broad concept representing personal beliefs and values, and religiosity, a narrower concept that refers to institutional beliefs and behaviors. They suggested that religiosity is a public issue, often expressed through group religious participation, whereas spirituality is a more private issue that may or may not be expressed publicly.

Religion is a part of spirituality, and for many people it is an expression of their spirituality; religion, however, does not comprise the total meaning of the broader concept (see Myers et al., 2000). Furthermore, many persons do not participate in or follow formal, institutionalized religious practices. As a consequence, when they equate spirituality and religion, these persons rightly reject the concept that spirituality is central to a sense of meaning and purpose in their lives.

It is interesting that various religious beliefs and traditions use reasonably compatible terms to define spiritual experience and growth. These beliefs include such concepts as belief in a God, a Creative Force, or a higher power; life after death; future retribution and reward; and various forms of ritual, sacrifice, and ceremonies that are specific to particular traditions or cultures (Ardell, 1996; Benjamin \& Looby, 1998; Ellis, 1991). In considering issues regarding the definition of and diversity in beliefs and practices, an inclusive definition of spirituality must be comprehensive enough to encompass all religious orientations toward spirituality but must not be limited by them in any way.

\section{Existing Definitions of Spirituality}

Professional counselors and educators have recognized the need to address, through assessment and intervention (Stanard, Sandhu, \& Painter, 2000), clients' spiritual concerns. Along with this recognition have come attempts by individuals in multiple disciplines to define spirituality. Traditionally, spirituality has been defined as a characteristic of all human beings, although possibly dormant in some, that enables individuals to transcend an egocentric life and experience the sacredness of the universe (Ardell, 1996; Frankl, 1984; Jung, 1933; Maslow, 1970). Fowler (1991) contended that spirituality is, foremost, the human capacity to construct and pursue meaning in life; it pro- 
duces, in some, a state of being that is very similar to Maslow's (1970) concept of transcendent self-actualization.

More recently, spirituality has been defined as personal beliefs that transcend the material aspects of existence and produce a sense of connectedness to the infinite (Myers et al., 2000; Shafranske \& Gorsuch, 1984; Witmer \& Sweeney, 1992). May (1982) identified spirituality as an experiential appreciation of life's meaning. The Association for Spiritual, Ethical and Religious and Values Issues in Counseling (ASERVIC) recently defined spirituality as "the animating life force ... unique to each person . . . that moves the individual toward greater knowledge, love, meaning, peace, hope, transcendence, connectedness, compassion, wellness, and wholeness"(http:// www.counseling.org/aservic/spirituality.html). Spirituality has also been proposed to be both a capacity and tendency within all humans to seek to move beyond where one is toward greater knowledge and love (Chandler et al., 1992).

Some authors have focused on spiritual experience as being the defining construct of human spirituality (Benjamin \& Looby, 1998; Chandler et al., 1992; Lukoff et al., 1998; Mack, 1994). For example, Hinkerkopf (1994) proposed that the experience of the spiritual is a felt phenomenon that moves individuals beyond their former frames of reference, bringing new meaning and understanding of themselves and others, leading to personal growth. Georgi (1999) conceptualized spirituality as the combination of the human capacities to make conscious choices, take risks, and relate to others, with the knowledge that there are realities that lie beyond an individual's understanding. He proposed that spirituality is the antithesis of the material aspects of human existence and "is not grounded in the content of existence but rather in the experience of its process" (Georgi, 1999, p. 1).

\section{A Conceptual and Operational Definition of Spirituality}

The aforementioned definitions of spirituality are representative of considerable progress toward establishing the useful and operational definition of spirituality referred to earlier. Therefore, drawing on the commonalities of these definitions, we propose that spirituality may be defined as the capacity and tendency present in all human beings to find and construct meaning about life and existence and to move toward personal growth, responsibility, and relationship with others. Spiritual experience and development is then operationalized as any experience or process in the life of an individual that creates new meaning and fosters personal growth as exhibited by the capacity to move beyond former frames of reference and risk change.

The definition of spirituality that we have proposed allows both religious beliefs/traditions and secular ideologies to coexist without loss of meaning. There is room for religiosity and rationalism and for individuals who are undecided about spiritual matters. The counselor or counselor educator can let the client or student define the trappings and boundaries of his or 
her particular orientation toward the spiritual and work to create an atmosphere that nurtures movement toward personal awareness, growth, and wellness. With this definition available and combined with the well-supported proposition that human spirituality is a universal phenomenon that is central to human growth and development and is an integral, if not the central component of true wellness, spirituality can no longer be considered merely a component of the person or a separate aspect of wellness. Rather, it is the integrating force that motivates and shapes the physical, psychological, and emotional functioning of all human beings.

\section{Discussion}

Our proposed definition requires an understanding of spirituality as central to holistic functioning. This concept is not new; it has been suggested either implicitly or explicitly in various wellness models (see Chandler et al., 1992; Myers et al., 2000; Sweeney \& Witmer, 1991). However, the centrality of spiritual experience in understanding human functioning and development has not found explicit application in the field of counseling as a whole. This is perhaps due to the tendency to equate spirituality with religiosity or even the reluctance to give credence to something that is less than empirical (Slife et al., 1999). Despite these obstacles, it is apparent that all helping professions are moving toward a more holistic understanding of life and wellness that incorporates the spiritual into all aspects of the human experience (Mack, 1994; Myers \& Truluck, 1998). This movement toward holistic wellness presents counselors and counselor educators with new challenges and the ethical responsibility to be competent in addressing clients' spiritual issues (Pargament \& Zinnbauer, 2000).

There are many counselor competencies suggested in the literature that complement this new view of human spirituality. In keeping with the definition of human spirituality and experience as unique to the individual, counselors need a firm grasp on the theory and principles of constructivism (Mahoney, 1991) and the application of these principles to the development of meaning and purpose in life, especially to the individual's religious beliefs. This perspective is ethically sound because it allows greater autonomy for the client and fosters the appreciation of diversity among clients' beliefs and values (Pargament \& Zinnbauer, 2000). Along with this perspective of spiritual constructivism is the need for counselors to be aware of and examine their own spiritual and religious constructions and the role these constructions have played in their own developmental processes (Burke \& Miranti, 1995; Grimm, 1994; Pargament \& Zinnbauer, 2000).

ASERVIC proposed a comprehensive body of counselor competencies in spirituality, suggesting that counselors should be able to describe their own spiritual belief system, identify life events that have shaped or developed it, and identify how their own spirituality has contributed to their wellness and general mental health (Summit on Spirituality, 1997). A counselor should 
also be aware of any personal spiritual/religious values that may interfere with demonstrating genuine empathy, openness, and acceptance of different spiritual values, beliefs, or phenomena of others (Burke \& Miranti, 1995; Grimm, 1994; Pargament \& Zinnbauer, 2000). A greater understanding of other spiritual/religious beliefs and traditions through education, training, and exposure to diverse religious communities and activities is also required of counselors, both to understand clients' perspectives and to identify possible conflicts with their own values and beliefs (Burke \& Maranti, 1995; Pargament \& Zinnbauer, 2000).

A wellness orientation toward spirituality would also require counselors to be knowledgeable about the theory and application of spirituality-centered wellness models and interventions (Kelly, 1995). One such model, discussed previously in this article, defines spiritual wellness as a balanced openness to development that neither represses nor is preoccupied with spirituality (Chandler et al., 1992). Interventions for individuals at both ends of a developmental continuum, and for those in the middle who could be considered spiritually balanced or well, are suggested. This model is consistent with the theoretical basis of the new Diagnostic and Statistical Manual of Mental Disorders (American Psychiatric Association, 2000) V62.89 diagnostic category for a spiritual or religious problem. This diagnostic code, which has its foundation in transpersonal psychology, addresses states of spiritual distress or emergency (Lukoff et al., 1998).

The Wheel of Wellness model suggests a similar holistic view of wellness, with spirituality being the central component (Myers et al., 2000; Witmer \& Sweeney, 1992). Using this model, a four-phase assessment and intervention process provides counselors with concrete direction for wellness-based treatment planning (Myers et al., 2000). The first phase requires clients to understand the model and concepts of wellness, beginning with a definition of spirituality such as the one that we proposed earlier in this article. A working knowledge of these models and others, combined with an understanding of the various spiritual development theories, is vital to the counseling process (Burke et al., 1999; Miller, 1999).

Spiritual wellness also implies the reality of spiritual "unwellness" (Chandler et al., 1992; Lukoff et al., 1998). Counselors should be knowledgeable of the negative and positive effects of religion and spirituality on the mental health of clients (Burke et al., 1999; Summit on Spirituality, 1997). Because many clients define their spirituality through their religious beliefs, it is imperative for counselors to understand the perspectives regarding the relationship between religiosity and mental health (see Dull \& Skokan, 1995; Ellis, 1991; Pargament \& Zinnbauer, 2000; Ventis, 1995).

\section{Implications}

As articles and books related to spiritual issues continue to proliferate in the field of counseling, it is clear that the profession is recognizing 
and accepting a mandate to integrate the spirituality of the individual into the therapeutic process. Several authors have recommended steps and strategies to incorporate spiritual issues into counselor preparation programs (e.g., Burke et al., 1999; Pate \& Bondi, 1992). In order to facilitate this movement and establish compatible and congruent preparation paradigms within counselor education programs, we present the following recommendations.

1. A developmentally based wellness orientation that promotes human spirituality as the core element of the individual may be a useful foundation for counselor preparation. Models, theories, and research compatible with this philosophy should receive concentrated attention, and complementary practicum experiences should be developed that foster students' self-awareness and self-assessment (Stanard et al., 2000).

2. Spirituality should be defined in a way that is inclusive of any spiritual or religious orientation but should clearly establish human spirituality as independent of religious, cultural, or scientific dogma. A constructivist orientation toward human spirituality should be taken to ensure the appreciation and regard for the uniqueness of every individual's spiritual values and meanings.

3. Counselors-in-training should be given opportunities to explore, understand, and articulate the personal meaning of their own spirituality as well as an understanding of the individual nature of their meaning-making processes. The ethical importance of a constructivist philosophy relative to spiritual issues should be stressed in professional orientation and continue throughout the educational process.

4. Counselors should be exposed to many diverse spiritual and religious beliefs, values, and phenomena as part of their preparation process. This could be greatly facilitated by integrating a developmental, wellness orientation in all core courses and in multicultural courses in the counseling curricula. Practicum experiences could be combined or coordinated to expose students simultaneously to cultural and spiritual diversity and development. For example, students could be encouraged to visit and participate in services of various faith traditions, both Eastern and Western, after which they would discuss their experiences and reactions in small and large groups during class or supervision times.

5. Counselors-in-training should be exposed to assessment and intervention techniques that are compatible with the philosophy of spiritual and holistic wellness. These techniques should be included in practicum experiences, and appropriate assessment instruments and strategies should be included in the measurement and assessment course curricula. For example, students could complete an available assessment of spiritual wellness, such as the one provided by Myers et al. (2000), and discuss the implications of their scores for their personal spiritual development. Furthermore, they can obtain supervised practice in the administration and interpretation of spiritual assessments, both for- 
mal and informal, and the development of appropriate interventions, based on assessment outcomes.

6. Research involving spiritual/religious issues and development should be encouraged and supported by counselor education programs. Master's-level research courses should include current and relevant articles in the area. Doctoral-level courses should address this area, specifically emphasizing the challenges and the need for further research. Counselors-in-training should be encouraged to complete dissertations that present the results of investigations of spiritual and religious issues.

7. Faculty should be actively involved in efforts to help students understand their own spiritual issues as well as those of their clients, and they should emphasize the integration of the construct of human spirituality throughout the entire program of study. To be effective in these roles, counselor educators will need to examine and be able to articulate their own understanding of spirituality and its relationship to the processes of human development and optimal functioning or wellness across the life span.

\section{Conclusion}

The evolution of the counseling profession has been based on a developmental, wellness philosophy. Part of that philosophy is a view of human functioning as holistic and oriented toward optimum growth. By applying a working definition of spirituality that is consistent with this philosophy, counselor educators can use holistic wellness paradigms as a foundation for preparing counselors to meet the unique needs of their clients more effectively.

\section{References}

Adler, A. (1954). Understanding human nature (W. B. Wolf, Trans.). New York: Fawcett Premier. (Original work published 1927)

American Psychiatric Association. (2000). Diagnostic and statistical manual of mental disorders (4th ed., Text rev.). Washington, DC: Author.

Archer, J., Probert, B. S., \& Gage, L. (1987). College students' attitudes toward wellness. Journal of College Student Personnel, 28, 311-317.

Ardell, D. B. (1996). The book of wellness: A secular approach to spirituality meaning and purpose. New York: Prometheus Books.

Benjamin, P., \& Looby, J. (1998). Defining the nature of spirituality in the context of Maslow's and Roger's theories. Counseling and Values, 42, 92-101.

Bergin, A. E., \& Jensen, J. P. (1990). Religiosity of psychotherapists: A national survey. Psychotherapy: Theory, Research, Practice, Training, 27, 3-7.

Bishop, D. R. (1992). Religious values as cross-cultural issues in counseling. Counseling and Values, 36, 179-191.

Burke, M. T., Hackney, H., Hudson, P., Miranti, J., Watts, G., \& Epp, L. (1999). Spirituality, religion, and the CACREP curriculum standards. Journal of Counseling \& Development, 77, 251-257.

Burke, M. T., \& Miranti, J. G. (1995). Counseling: The spiritual dimension. Alexandria, VA: American Counseling Association. 
Chandler, C., Holden, J., \& Kolander, C. (1992). Counseling for spiritual wellness: Theory and practice. Journal of Counseling \& Development, 71, 168-175.

Council for Accreditation of Counseling and Related Educational Programs. (2001). Accreditation manual. Alexandria, VA: Author.

Dull, V. T., \& Skokan, L. (1995). A cognitive model of religions influence on health. Journal of Social Issues, 5, 49-64.

Dunn, H. L. (1961). High-level wellness. Arlington, VA: R. W. Beatty.

Ellis, A. (1991). The case against religiosity. In C. Bufe (Ed.), Alcoholics anonymous: Cult or cure? San Francisco: Sharpe Press.

Erikson, E. (1963). Childhood and society. New York: Norton.

Fowler, J. W. (1981). Stages of faith: The psychology of human development and quest for meaning. New York: Harper \& Row.

Fowler, J. W. (1991). Stages in faith consciousness. New Directions in Child Development, 52 , $27-45$.

Frankl, V. E. (1984). Man's search for meaning. New York: Pocket Books.

Freud, S. (1959). Recommendations for physicians practicing psychoanalysis. In Collected papers of Sigmund Freud (Vol. 2, pp. 323-333). New York: Basic Books. (Original work published 1912)

Gallup, G., Jr. (1985). Religion in America: The Gallup report (Report No. 236). Princeton, NJ: Author.

Gallup, G., Jr., \& Castelli, J. (1989, June 3). 8 in 10 find comfort in religion, survey says. Washington Post, p. 19.

Gallup, G., Jr., \& Lindsay, D. M. (1999). Surveying the religious landscape: Trends in U.S. beliefs. Harrisburg, PA: Morehouse.

Georgi, J. M. (1999). Spirituality: A clinical response. Unpublished manuscript.

Grimm, D. W. (1994). Therapist spiritual and religious values in psychotherapy. Counseling and Values, 38, 154-165.

Grof, S. (1999). Technologies of the sacred (Part 2). International Journal of Humanities and Peace, 15, 93-94.

Hettler, W. (1984). Wellness: Encouraging a lifetime pursuit of excellence. Health Values: Achieving High Level Wellness, 8, 13-17.

Hinterkopf, E. (1994). Integrating spiritual experiences in counseling. Counseling and Values, $38,165-175$.

Jung, C. J. (1933). Modern man in search of a soul. New York: Harcourt Brace.

Kelly, E. W., Jr. (1994). The role of religion in counselor education: A national survey. Counselor Education \& Supervision, 33, 227-237.

Kelly, E. W., Jr. (1995). Spirituality and religion in counseling and psychotherapy: Diversity in theory and practice. Alexandria, VA: American Counseling Association.

Kelly, E. W., Jr. (1997). Religion and spirituality in various counselor training programs: A comment on Pate and High. Counseling and Values, 42, 7-11.

Kohlberg, L. (1984). The psychology of moral development. New York: Harper \& Row.

Lehman, C. (1993, January 30). Faith-based counseling gains favor. The Washington Post, pp. 7-8.

Levinson, D., Darrow, C., Kline, E., Levinson, M., \& McKee, B. (1978). The seasons of a man's life. New York: Knopf.

Lukoff, D., Lu, F., \& Turner, R. (1998). From spiritual emergency to spiritual problem. Journal of Humanistic Psychology, 38, 21-51.

Mack, M. L. (1994). Understanding spirituality in counseling psychology. Counseling and Values, $39,15-32$.

Mahoney, M. (1991). Human change processes: The scientific foundations of psychotherapy. New York: Basic Books.

Maslow, A. H. (1970). Motivation and personality (2nd ed.). New York: Harper \& Row.

May, G. (1982). Will and spirit: A contemplative psychology. San Francisco: Harper \& Row.

Miller, G. (1999). The development of the spiritual focus in counseling and counselor education. Journal of Counseling \& Development, 77, 498-501. 
Myers, J. E. (1991). Wellness as the paradigm for counseling and development: The possible future. Counselor Education and Supervision, 30, 183-193.

Myers, J. E. (Ed.). (1992). Wellness throughout the life span [Special issue]. Journal of Counseling \& Development, 71(2).

Myers, J. E., Sweeney, T. J., \& Witmer, J. M. (2000). The wheel of wellness, counseling for wellness: A holistic model for treatment planning. Journal of Counseling \& Development, $78,251-266$.

Myers, J. E., \& Truluck, M. (1998). Health beliefs, religious values, and the counseling process. Counseling and Values, 42, 106-123.

Nino, A. G. (1997). Assessment of spiritual quests in clinical practice. International Journal of Psychology, 2, 193-213.

Palmo, A., \& Weikel, W. (1986). Foundations of mental health counseling. Springfield, IL: Thomas.

Pargament, K. I., \& Zinnbauer, B. J. (2000). Working with the sacred: Four approaches to religious and spiritual issues in counseling. Journal of Counseling \& Development, 78, 162-171.

Pate, R. H., \& Bondi, A. M. (1992). Religious belief and practice: An integral aspect of multicultural awareness. Counselor Education and Supervision, 32, 108-115.

Pate, R. H., \& High, H. J. (1995). The importance of client religious beliefs and practices in the education of counselors in CACREP-accredited programs. Counseling and Values, 40, 2-5.

Piaget, J. (1963). The origins of intelligence in children. New York: Norton. (Original work published 1926)

Quackenbos, S., Privette, G., \& Klentz, B. (1985). Psychotherapy: Sacred or secular. Journal of Counseling and Development, 63, 290-293.

Riker, H. C., \& Myers, J. E. (1990). Retirement counseling: A practical guide for action. New York: Hemisphere.

Rizzuto, A. M. (1991). Religious development: A psychoanalytic point of view. New Directions for Child Development, 52, 47-60.

Shafranske, E. P., \& Gorsuch, R. L. (1984). Factors associated with the perception of spirituality in psychology. Journal of Transpersonal Psychology, 16, 231-241.

Slife, B. D., Hope, C., \& Nebeker, R. S. (1999). Examining the relationship between religious spirituality and psychological science. Journal of Humanistic Psychology, 39, 51-86.

Smith, H. B. (1999). Managed care: A survey of counselor educators and counselor practitioners. Journal of Mental Health Counseling, 21, 270-284.

Spero, M. H. (1992). Religious objects as psychological structures. Chicago: University of Chicago Press.

Stanard, R. P., Sandhu, D. S. \& Painter, L. C. (2000). Assessment of spirituality in counseling. Journal of Counseling \& Development, 78, 204-210.

Strohl, J. E. (1998). Transpersonalism: Ego meets soul. Journal of Counseling \& Development, $76,397-404$.

Summit on spirituality: Counselor competencies (May 1996 rev.). (1997, Spring). ACES Spectrum, 57, 16.

Sweeney, T. J. (1998). Adlerian counseling: A practitioners approach. Philadelphia: Accelerated Development.

Sweeney, T. J., \& Witmer, J. M. (1991). Beyond social interest: Striving toward optimal health and wellness. Individual Psychology, 47, 527-540.

Ventis, W. L. (1995). The relationships between religion and mental health. Journal of Social Issues, 51, 33-48.

Witmer, J. M., \& Sweeney T. J. (1992). A holistic model for wellness and prevention over the life span. Journal of Counseling \& Development, 71, 140-148.

Young, J. S., Cashwell, C. S., \& Woolington, V. J. (1998). The relationship of spirituality to cognitive and moral development and purpose in Life. Counseling and Values, 43, 63-70. 